\title{
Increasing Chlorophyll $a$ Amid Stable Nutrient Concentrations in Rhode Island Lakes and Reservoirs
}

\author{
Hollister. J. W. * ${ }^{1}$, Kellogg, \\ D. Q. ${ }^{2}$, Krea \\ Green, L. ${ }^{2}$, Gold, A. ${ }^{2}$
}

${ }^{1}$ US Environmental Protection Agency, Office Of Research and Development, Atlantic Coastal Environmental Sciences Division, Narragansett, RI 02882

2 University of Rhode Island, Department of Natural Resources Science, Kingston, RI 02881

${ }^{3}$ ORISE, Narragansett, RI 02882

**corresponding author: hollister.jeff@epa.gov*

Addressing anthropogenic impacts on aquatic ecosystems is a focus of lake management. Controlling phosphorus and nitrogen can mitigate these impacts, but determining management effectiveness requires long-term datasets. Recent analysis of the LAke multi-scaled GeOSpatial and temporal database for the Northeast (LAGOSNE) United States found stable water quality in the northeastern and midwestern United States, however, sub-regional trends may be obscured. We analyze a sub-regional (i.e., $3000 \mathrm{~km}^{2}$ ) trend with the University of Rhode Island's Watershed Watch Volunteer Monitoring Program (URIWW) dataset. URIWW has collected water quality data on Rhode Island lakes and reservoirs for over 25 years. The LAGOSNE and URIWW datasets allow for comparison of water quality trends at regional and sub-regional extents, respectively. We assess regional (LAGOSNE) and state (URIWW) trends with yearly mean anomalies calculated on a per-station basis. Sub-regionally, temperature and chlorophyll $a$ increased from 1993 to 2016. Total nitrogen shows a weak increase driven by low years in the early 1990s. Total phosphorus and the nitrogen:phosphorus ratio (N:P) were stable. At the regional scale, the LAGOSNE dataset shows similar trends to prior studies of the LAGOSNE with chlorophyll $a$, total nitrogen, total phosphorus, and N:P all stable over time. In short, algal biomass, as measured by chlorophyll $a$ in Rhode Island lakes and reservoirs is increasing, despite stability in total nitrogen, total phosphorus, and the nitrogen to phosphorus ratio. This analysis suggests an association between lake temperature and primary production. Additionally, we demonstrate both the value of long-term monitoring programs, like URIWW, for identifying trends in environmental condition, and the utility of site-specific anomalies for analyzing for long-term water quality trends.

\section{Introduction}

Aquatic ecosystems have been altered as the result of human activities modifying nutrient cycling on a global scale (Vitousek et al. 1997, Filippelli 2008, Finlay et al. 2013). Because of their position in the landscape, lakes can function as integrators and sentinels for these anthropogenic effects (Williamson et al. 2008, Schindler 2009). Increasing nutrient inputs, particularly of nitrogen $(\mathrm{N})$ and phosphorus $(\mathrm{P})$, derived from intensive agriculture and densely populated urban areas have contributed to the eutrophication of many lakes 
35 (Carpenter et al. 1998, Smith 2003). This eutrophication often leads to an increase in the

36 frequency and severity of harmful algal blooms, greater risks for human and animal health,

37 and potential economic costs associated with eutrophic waters (Dodds et al. 2008, Paerl

38 and Huisman 2009, Kosten et al. 2012, Michalak et al. 2013, Taranu et al. 2015, Brooks et al.

39 2016). To address these problems, management strategies have historically focused on

40 reducing $\mathrm{P}$ inputs to lakes, but research also suggests that reducing $\mathrm{N}$ inputs may be more

41 effective in certain situations (Schindler et al. 2008, Paerl et al. 2016). These studies

42 indicate that relationships between $\mathrm{N}, \mathrm{P}$, and chlorophyll $a$ exist and these relationships are

43 spatially and temporally complex. Thus, long-term data are needed to identify trends at

44 local, regional, and national scales.

45 Lake datasets that cover longer time periods and broader spatial scales are now becoming

46 available. Programs such as the US Environmental Protection Agency's National Lakes

47 Assessment (NLA) provide data that allow for continental-scale water quality analysis.

48 These data allow for analyses that can be useful for managing water resources by

49 developing water quality criteria for N, P, and chlorophyll $a$ (Herlihy et al. 2013, Yuan et al.

50 2014). Studying temporal trends across large spatial scales can illustrate the effects of

51 eutrophication such as the degradation of oligotrophic systems as P increases (Stoddard et

52 al. 2016). Broad-scale data can also be used for water quality modeling across a range of

53 spatial scales including for predicting lake trophic state, which is indicative of ecosystem

54 condition (Hollister et al. 2016, Nojavan et al. 2019). These trophic state models indicate

55 that landscape variables (e.g., ecoregion, elevation, and latitude) are important and that

56 regional trends exist. Lake-specific drivers have also been shown to be important for

57 predicting continental-scale water quality which adds an additional layer of complexity

58 (Read et al. 2015). Despite these challenges, it is important to study lakes at multiple

59 spatial scales because emergent trends on regional or continental scales may or may not be

60 present in individual lakes (Cheruvelil et al. 2013, Lottig et al. 2014).

61 Previous studies using regional data from the northeastern and midwestern United States

62 (US) have investigated spatial and temporal water quality trends and have shown

63 differences based on scale. Macro-scale (i.e., subcontinental) drivers of water quality trends

64 are complex and may vary temporally (Lottig et al. 2017). This complexity can cause 
nutrient ( $\mathrm{N}$ and $\mathrm{P}$ ) trends to have different drivers than ratios of the nutrients (Collins et al. 2017). On a regional scale, trends of N, P, and chlorophyll $a$ differ as factors such as land use and climate vary between regions, particularly when comparing the northeastern and midwestern US (Filstrup et al. 2014, 2018). Thus, it was surprising when little change in nutrients and chlorophyll $a$ was reported over a 25 year period for these regions (Oliver et al. 2017). Given what is known about long-term trends in water quality within the broader region of the northeastern United States (US), we were curious if the lack of trends was also present in water quality at a sub-regional scale, using data on the $3,000 \mathrm{~km}^{2}$ area that encompasses a number of Rhode Island lakes and reservoirs.

74 Examining long-term trends in Rhode Island lakes is possible because of the data gathered 75 by University of Rhode Island's Watershed Watch (URIWW). URIWW is a scientist-led 76 citizen science program founded in the late 1980s that has built a robust collaboration between URI scientists and a vast network of volunteer monitors. Volunteer monitors are trained and then collect in situ data as well as whole water samples during the growing season (e.g., May through October). The entire effort follows rigorous quality control/quality assurance protocols. These types of citizen science efforts allow for the collection of reliable data that in turn lead to crucial and frequently unexpected insights

82 (Dickinson et al. 2012, Kosmala et al. 2016, Oliver et al. 2017). URIWW data contributed to 83 the larger regional study by Oliver et al. (2017), and, also allowed us to examine the long84 term trends specifically in Rhode Island.

85 The goals of this study were to examine $\sim 25$ years of lake and reservoir data in Rhode 86 Island and answer two questions. First, are there state-wide trends in total nitrogen (TN), 87 total phosphorus (TP), total nitrogen to total phosphorus ratio (TN:TP), chlorophyll $a$, and 88 lake temperature? Second, are water quality trends in Rhode Island similar to regional 89 trends in the northeastern United states? Another objective of this paper was to apply 90 existing methods for examining long-term climate records (e.g., Jones and Hulme 1996) to 91 water quality data in order to examine long-term trends. We conducted this analysis using 92 open data from the URI Watershed Watch program and the LAke multi-scaled GeOSpatial 93 and temporal database for the Northeast (LAGOSNE) project and the analysis in its entirety 94 is available for independent reproduction at https://github.com/usepa/ri_wq_trends and 
95 is archived at https://doi.org/10.5281/zenodo.3662828 (Soranno et al. 2017, Stachelek

96 and Oliver 2017, Hollister et al. 2019).

\section{$97 \quad 2$ Methods}

98 For this study, we combined a long-term dataset on water quality of lakes in Rhode Island 99 with a trend analysis based on water quality anomalies (i.e., measured values with the long

100 term mean subtracted) to find increasing or decreasing annual water quality trends. Details

101 are outlined below.

\section{$102 \quad 2.1$ Study Area and Data}

103 The study area for this analysis includes lakes and reservoirs in the state of Rhode Island

104 where data were collected by the University of Rhode Island's Watershed Watch program

105 (Figure 1). The URIWW program began in 1988, monitoring 14 lakes and has now grown to

106 include over 250 monitoring sites on over 120 waterbodies, including rivers/streams, and

107 estuaries, with more than 400 trained volunteers. URIWW now provides more than $90 \%$ of

108 Rhode Island's lake baseline data and is an integral part of the state's environmental data

109 collection strategy. Data quality assurance and control is treated with paramount

110 importance; volunteers are trained both in the classroom and the field, regular quality

111 checks occur, and volunteers are provided with all the necessary equipment and supplies,

112 along with scheduled collection dates. For freshwater lakes and reservoirs, weekly secchi

113 depth and water temperature are recorded, along with bi-weekly chlorophyll $a$ and in deep

114 lakes (greater than 5 meters) dissolved oxygen. Water samples are collected three times

115 per season (May through October) to be analyzed for nutrients and bacteria. 
bioRxiv preprint doi: https://doi. org/10.1101/2020.02.11.944280; this version posted February 12, 2020. The copyright holder for this preprint (which was not certified by peer review) is the author/funder. This article is a US Government work. It is not subject to copyright under 17 USC 105 and is also made available for use under a CCO license.

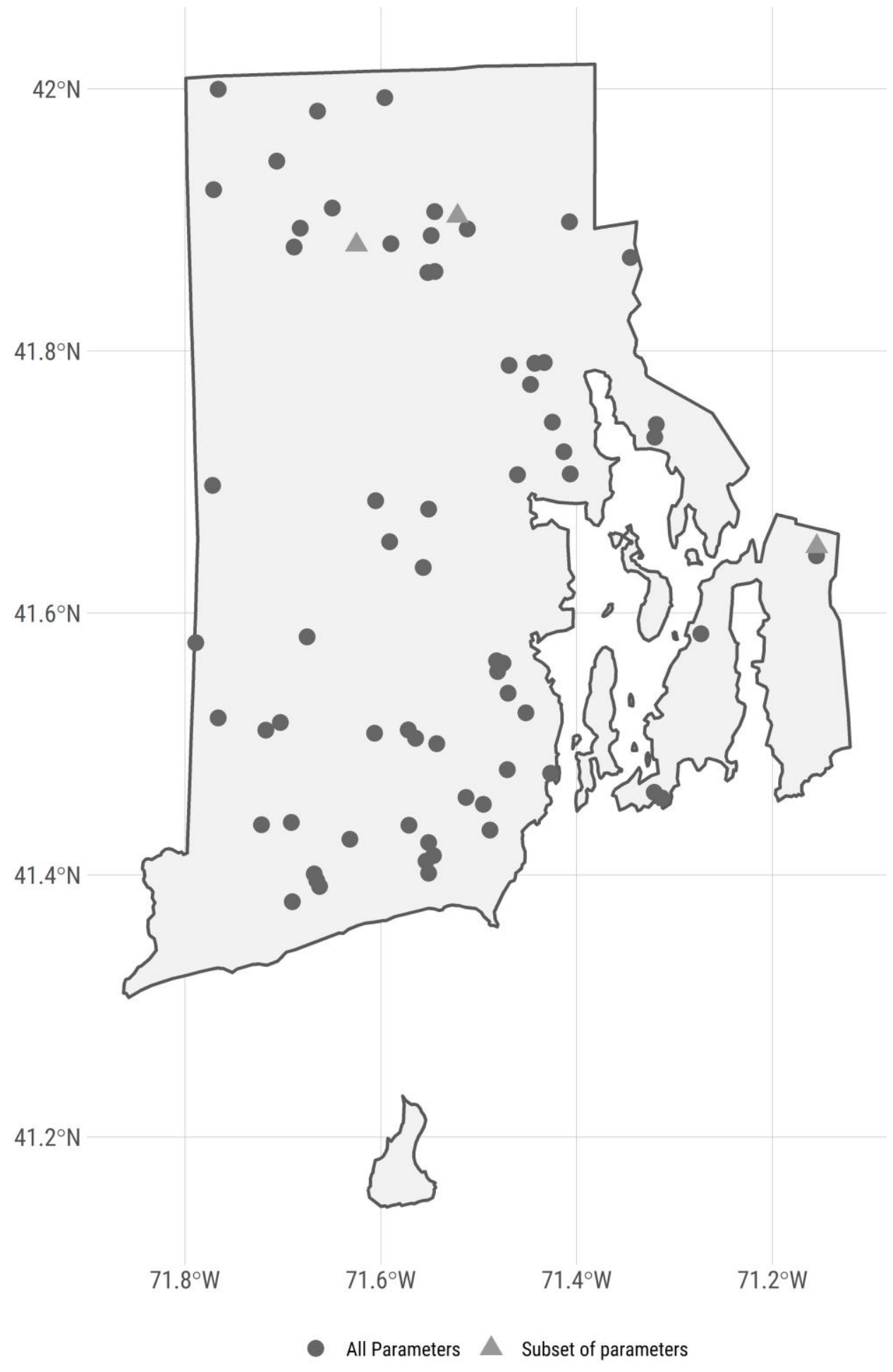


118 For this analysis, we were interested in trends in lake temperature, TN, TP, TN:TP, and

119 chlorophyll $a$. In particular, we selected URIWW data that matched the following criteria:

120 1) were sampled between 1993 and 2016, 2) were sampled in May to October, 3) and were

121 sampled at a depth of 2 meters or less. As not all sites have data for all selected years, we

122 further filtered the data to select sites that had at least 10 years of data for a given

123 parameter within the 1993 to 2016 time frame. The final dataset used in our analysis

124 included 69 lakes and reservoirs. Of these sites, our filtered dataset had approximately 67

125 sites measured for temperature, 67 sites measured for chlorophyll $a, 69$ sites measured for

126 TN, and 69 sites measured for TP. Of the 69 sampling sites, 66 had data for all 5

127 parameters. The N:P ratio was calculated by dividing the mass concentrations of total

128 nitrogen and total phosphorus and then converting to a molar ratio by multiplying by 2.21

129 (e.g., atomic weight of P 30.974/atomic weight of $N$ 14.007).

130 Field and analytical methods are detailed on the URIWW website at

131 https://web.uri.edu/watershedwatch/uri-watershed-watch-monitoring-manuals/ and

132 https://web.uri.edu/watershedwatch/uri-watershed-watch-quality-assurance-project-

133 plans-qapps/, respectively. These methods, approved by both the state of Rhode Island and

134 the US Environmental Protection Agency, have remained fairly consistent, although over

135 the nearly 30 years changes did occur. When new methods were introduced, comparisons

136 between old and new methods were conducted and in all cases no statistically significant

137 differences were found with the new methods. Furthermore, the new methods did at times

138 improve the limits of detection; however, this impacted a very small number (less than 1\%)

139 of measurements in this study. We did run our analyses (see Water Quality Trend

140 Analysis section) with all data and with only those data greater than the detection limit.

141 There was no change in the trend analysis and thus, the results we report are for all data as

142 originally reported in the URIWW dataset. Given these results, we assume the data to be

143 consistent across the reported time period and appropriate for a long term assessment of

144 trends.

145 Prior studies have modeled water quality trends across a larger region of the northeastern

146 US that included 17 states including Minnesota, Wisconsin, Iowa, Missouri, Illinois, Indiana,

147 Michigan, Ohio, Pennsylvania, New York, New Jersey, Connecticut, Massachusetts, Rhode 
148 Island, Vermont, New Hampshire, and Maine (Soranno et al. 2015, Oliver et al. 2017). We

149 repeated our analysis (see Water Quality Trend Analysis section) with the same dataset

150 used by Oliver et al. (2017), the LAGOSNE dataset (Soranno et al. 2015, 2017, Stachelek and

151 Oliver 2017). Temperature data were not available, thus we examined trends, using our

152 analytical methods, for TN, TP, TN:TP, and chlorophyll $a$ from the LAGOSNE dataset. We

153 used the same selction criteria on the LAGOSNE dataset as was applied to the URIWW data.

\section{$154 \quad 2.2$ Water Quality Trend Analysis}

155 There are many different methods for analyzing time series data for trends. Environmental 156 data are notoriously "noisy" and one of the difficulties that is encountered with multiple

157 sampling locations is how to identify a trend while there is variation within a sampling site

158 as well as variation introduced by differing start years for sampling among the many sites.

159 For instance, if long-term data on water quality were collected more frequently in early

160 years from more pristine waterbodies, then a simple comparison of raw values over time

161 might show a decrease in water quality, which could be misleading if later sampling

162 occurred on both pristine and more eutrophic water bodies. Thus, it is necessary to account

163 for this type of within-site and among-site variation, using methods similar to those used to

164 analyze long-term temperature trends using temperature anomalies (e.g., Jones and Hulme

165 1996). The general approach we used calculates site-specific deviations from a long-term

166 mean over a pre-determined reference period. This allowed all sites to be shifted to a

167 common baseline and the deviations, or anomalies, indicate change over the specified

168 reference period. We refer to this method as "site-specific anomalies".

\section{$169 \quad$ 2.2.1 Summarizing site-specific anomalies}

170 Methods for calculating the site-specific anomalies and the yearly means are as follows and

171 are presented graphically in Figure 2. Additionally, an example R script,

172 schematic_anomaly.R and example dataset, schematic.csv to recreate and demonstrate

173 the calculations in Figure 2 is available from at https://github.com/usepa/ri_wq_trends

174 and is archived at https://doi.org/10.5281/zenodo.3662828 (Hollister et al. 2019). 


\begin{tabular}{|c|c|c|c|c|c|c|}
\hline \multirow[b]{2}{*}{$\begin{array}{l}\text { Station } 1 \\
\text { Long-term } \\
\text { mean }=7.06\end{array}$} & \multicolumn{2}{|r|}{ Year 1} & \multicolumn{2}{|r|}{ Year 2} & \multicolumn{2}{|r|}{ Year 3} \\
\hline & $\begin{array}{c}\text { data } \\
5 \\
4 \\
8\end{array}$ & $\begin{array}{l}\text { Site and Year mean } \\
5.67 \\
\text { Site and Year Anomaly } \\
5.67-7.06=-1.39\end{array}$ & $\begin{array}{c}\text { data } \\
6 \\
9 \\
6\end{array}$ & $\begin{array}{c}\text { Site and Year mean } \\
7 \\
\text { Site and Year Anomaly } \\
7-7.06=-0.057\end{array}$ & $\begin{array}{c}\text { data } \\
8 \\
9\end{array}$ & $\begin{array}{l}\text { Site and Year mean } \\
\qquad 8.5 \\
\text { Site and Year Anomaly } \\
8.5-7.06=\mathbf{1 . 4 4}\end{array}$ \\
\hline
\end{tabular}

\begin{tabular}{l|c|c} 
Station 2 & data & Site and Year mean \\
Long-term & 2 & 3 \\
mean $=3.66$ & 3 & Site and Year Anomaly \\
& 3 & $3-3.66=-0.67$ \\
& 4 &
\end{tabular}

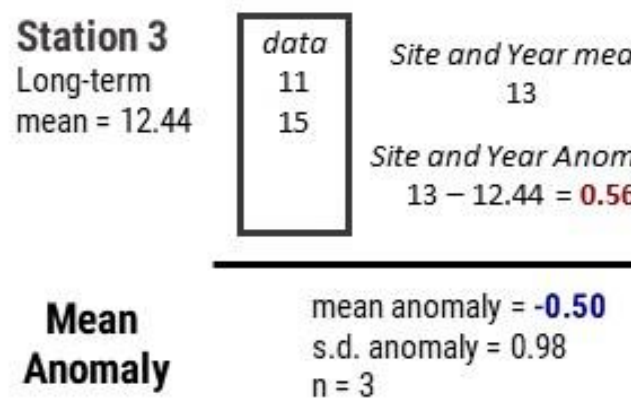

\section{Anomaly}

$$
\mathrm{n}=3
$$

mean anomaly $=0.75$

s.d. anomaly $=1.14$

$n=2$

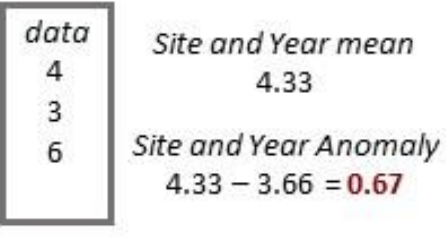

Site and Year Anomaly
$4.33-3.66=0.67$

Site and Year mean

10.33

Site and Year Anomaly

$10.33-12.44=-2.11$

176 Figure 2: Example calculation of the site-specific anomalies and yearly mean anomalies.

177 The general steps, outlined in Figure 2 and listed below, are repeated for each of the water

178 quality parameters.

179 1. For each site, calculate the annual means, producing a single mean value for each site

180 and year. This step prevents bias from pseudoreplication of multiple measurements of

181 the same site in a given year (Hurlbert 1984). The per site means across years are

182 assumed to be independent.

183 2. Calculate the long-term reference mean for each site. This results in a single long-term 184 mean for each of the sites.

185 3. Calculate the anomaly for each annual mean at each site by subtracting the annual and 186 reference means.

187 4. Summarize by calculating the mean anomaly per year for the entire group of sites. The 188 resultant values are analyzed for a trend over time. 


\subsubsection{Linear regression on annual mean anomalies}

190 Testing for a regression slope being different than zero can be used to test for monotonic

191 trends in water quality data (Helsel and Hirsch 2002). We used these standard procedures

192 to test for positive or negative trends in lake temperature, chlorophyll $a$, TN, TP and TN:TP.

193 For each parameter, we fit a regression line to the anomalies as a function of year and

194 tested the null hypothesis that no trend existed (e.g., $\beta_{1}=0$ ). The slope of this line provides

195 information on the mean yearly change of that paramter over the time period studied.

196 Traditionally, trends would be determined by assessing "significance" but recent guidelines

197 suggest not using arbitrary p-value cut-offs to assesses significance (Wasserstein et al.

198 2016). Our interpretation of the trends attempts to follow this advice and we assess trends

199 with the information provided by the magnitude of the slopes, the p-values, and our

200 understanding of the processes involved.

\section{2.2.3 Comparison of Rhode Island to the region}

202 Oliver et al. (2017) used hierarchical linear models and showed relatively stable water

203 quality in the lakes of the northeastern United States. While the University of Rhode

204 Island's Watershed Watch data were included in this regional study, we hypothesized that

205 in the case of Rhode Island regional trends were masking sub-regional trends. Therefore,

206 we decided to reanalyze the LAGOSNE data to compare the trends at the regional scale to

207 the trends at the Rhode Island state scale using the site-specific anomaly and trend analysis

208 approach outlined above.

\section{Results}

210 During the period of 1993 to 2016, Rhode Island lakes and reservoirs in our dataset had a

211 mean lake temperature of $21.9^{\circ} \mathrm{C}$, mean TN of $600 \mu \mathrm{g} / \mathrm{l}$, mean TP of $24 \mu \mathrm{g} / \mathrm{l}$, mean TN:TP

212 ratio of 84.17 molar, and mean chlorophyll $a$ of $10.1 \mu \mathrm{g} / \mathrm{l}$ (Table 1 ). 


\begin{tabular}{cccccc} 
Parameter & Units & Mean & Median & Max & Std. Dev \\
\hline Temperature & ${ }^{\circ} \mathrm{C}$ & 21.9 & 22.2 & 29 & 1.9 \\
Total Nitrogen & $\mu \mathrm{g} / \mathrm{l}$ & 600 & 475 & 4670 & 425 \\
Total Phosphorus & $\mu \mathrm{g} / \mathrm{l}$ & 24 & 15 & 325 & 30 \\
N:P & molar & 84.17 & 71.08 & 827.2 & 57.9 \\
Chlorophyll & $\mu \mathrm{g} / \mathrm{l}$ & 10.1 & 4.5 & 666.2 & 22.1
\end{tabular}

215 Table 1: Summary statistics for URI Watershed Watch data from 1993 to 2016.

216 For lakes and reservoirs in the larger region represented by the LAGOSNE States, mean TN

217 was $855 \mu \mathrm{g} / \mathrm{l}$, mean TP was $32 \mu \mathrm{g} / \mathrm{l}$, mean TN:TP ratio was 90.37 molar, and mean

218 chlorophyll $a$ was $16.8 \mu \mathrm{g} / \mathrm{l}$ (Table 2).

\begin{tabular}{cccccc} 
Parameter & Units & Mean & Median & Max & Std. Dev \\
\hline Total Nitrogen & $\mu \mathrm{g} / \mathrm{l}$ & 855 & 560 & 16780 & 1205 \\
Total Phosphorus & $\mu \mathrm{g} / \mathrm{l}$ & 32 & 16 & 1200 & 54 \\
$\mathrm{~N}: \mathrm{P}$ & molar & 90.37 & 59.18 & 88474 & 1029 \\
Chlorophyll & $\mu \mathrm{g} / \mathrm{l}$ & 16.8 & 6.2 & 696 & 30.4
\end{tabular}

219 Table 2: Summary statistics for LAGOSNE data from 1993 to 2016.

\section{$220 \quad 3.1$ State-wide trends in water quality}

221 Mean annual temperature anomalies in lakes and reservoirs appears to be increasing

222 (slope $=0.053, \mathrm{p}=0.0062$ ) with the majority of years with mean temperature greater than

223 the long-term mean occurring in recent years (Figure 3). Chlorophyll $a$ is also showing an

224 increasing trend over time (slope $=0.29, \mathrm{p}=0.0000008$ ) and with the exception of a

225 slightly above-average year in 2003 , the above-average years have all occurred in the most 226 recent years (Figure 4A.). 
227 Mean annual trends for nutrients were weaker or showed no trend over time. The data

228 suggest a positive trend in TN (slope $=3.8, \mathrm{p}=0.00022$ ); however, that perceived trend is

229 driven by the lower than mean TN values in 1993 and 1994 (Figure 5A.). Since 1995, the

230 yearly trend shows a lower increase over time (slope $=2.5, \mathrm{p}=0.0067$ ). TP does not show a

231 trend over time in the yearly anomalies (slope $=0.11, p=0.062$ ) and years that are over or

232 under the mean are more evenly distributed over the years (Figure 6A.). The pattern is the

233 same for the TN:TP ratio (slope $=0.18, p=0.71$ ) with little evidence suggesting a change in

234 the concentrations of TN relative to the concentrations of TP (Figure 7A.). Data for all

235 figures are available as a comma-separated values file, yearly_average_anomaly.csv from

236 at https://github.com/usepa/ri_wq_trends and is archived at

237 https://doi.org/10.5281/zenodo.3662828 (Hollister et al. 2019). 


\section{URI Watershed Watch Temperature}

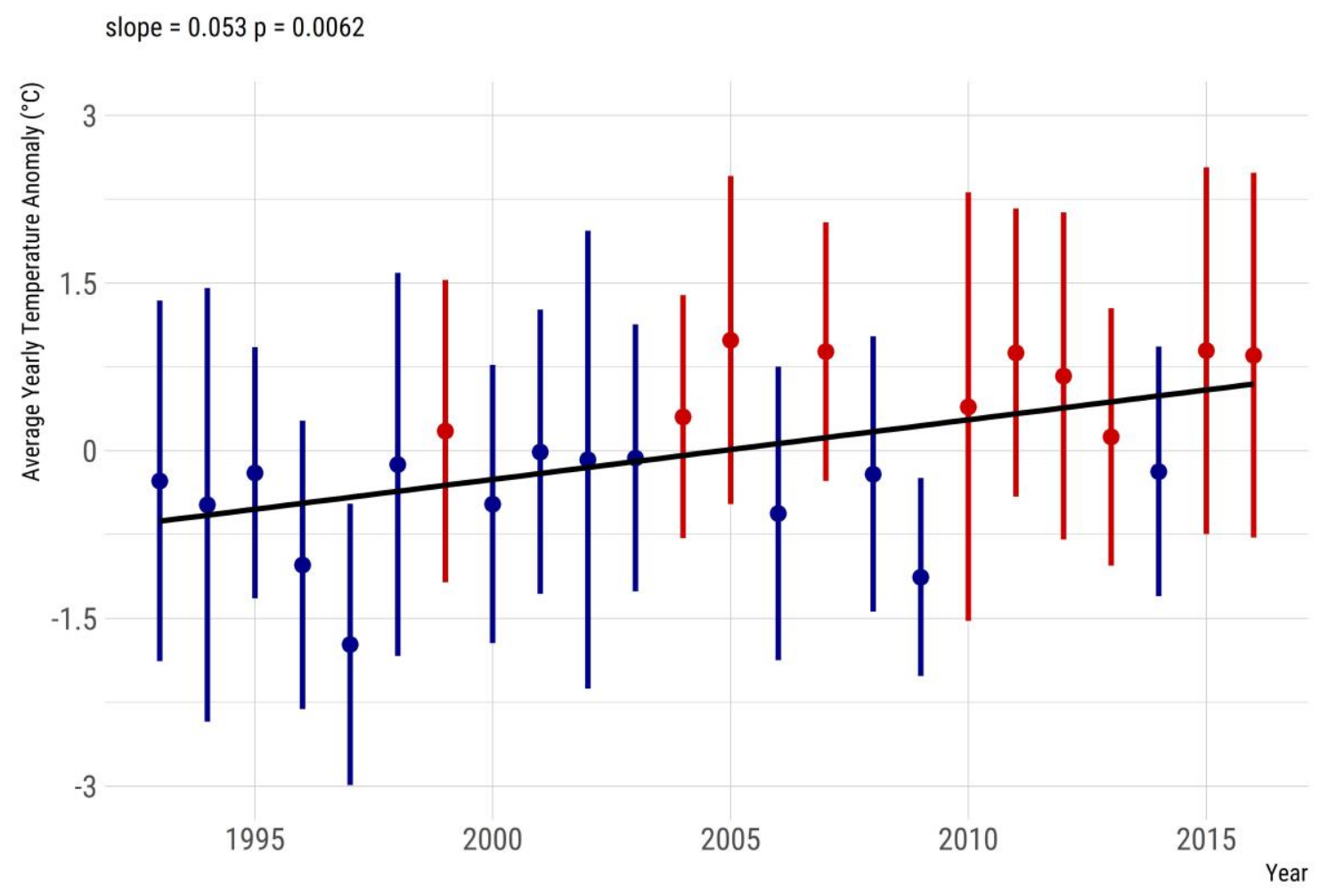

241 Figure 3: Yearly trend over 20+ years of lake temperature (mean anomaly) in Rhode Island 242 lakes and reservoirs. Points are means of site-specific anomalies and ranges are standard 243 deviations of site-specific anomalies. Blue indicates yearly site-specific anomalies that were, 244 on average, below the site-specific long-term means. Red indicates yearly site-specific 245 anomalies that were, on average, above the site-specific long-term means. 


\section{A. URI Watershed Watch Chlorophyll}

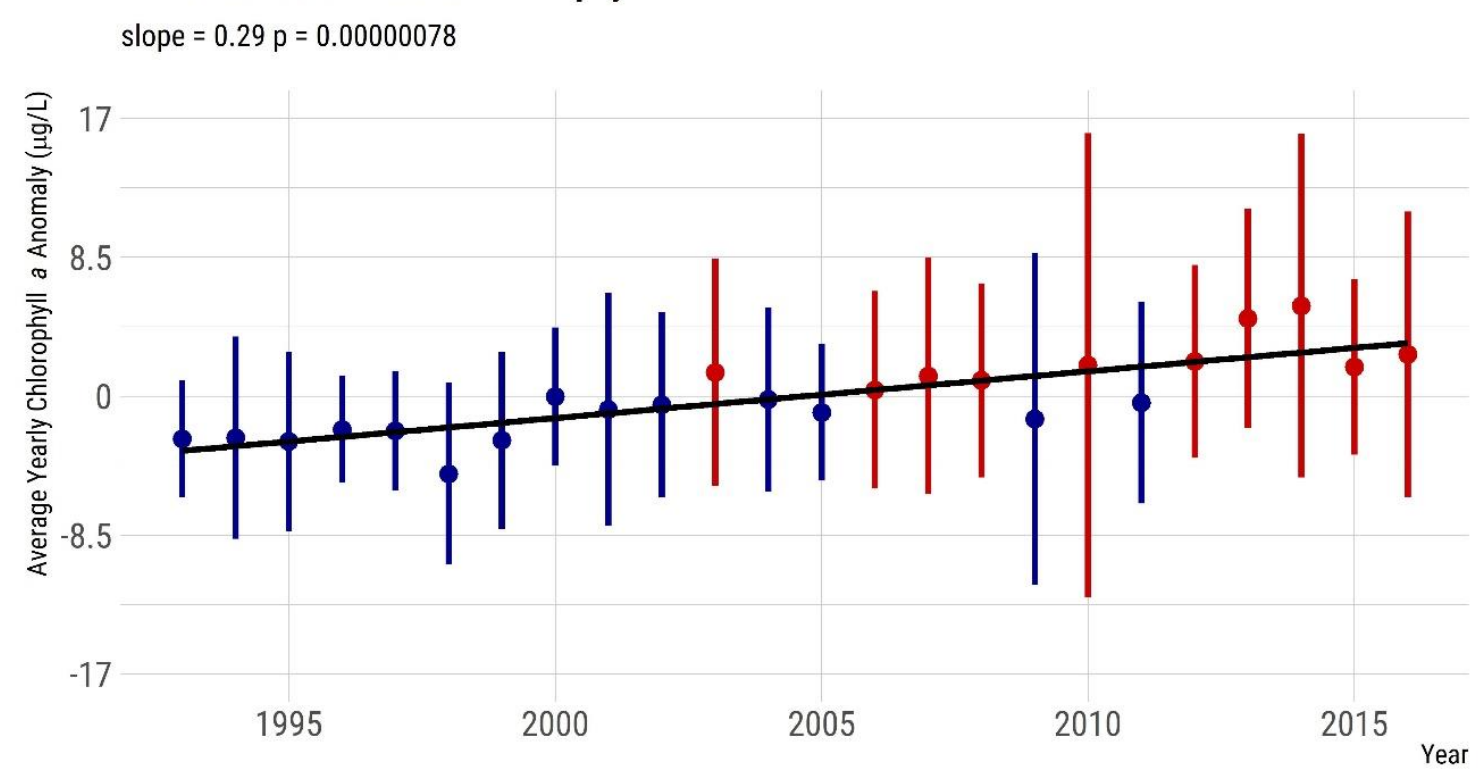

\section{B. LAGOSNE Chlorophyll}

slope $=0.027 p=0.58$

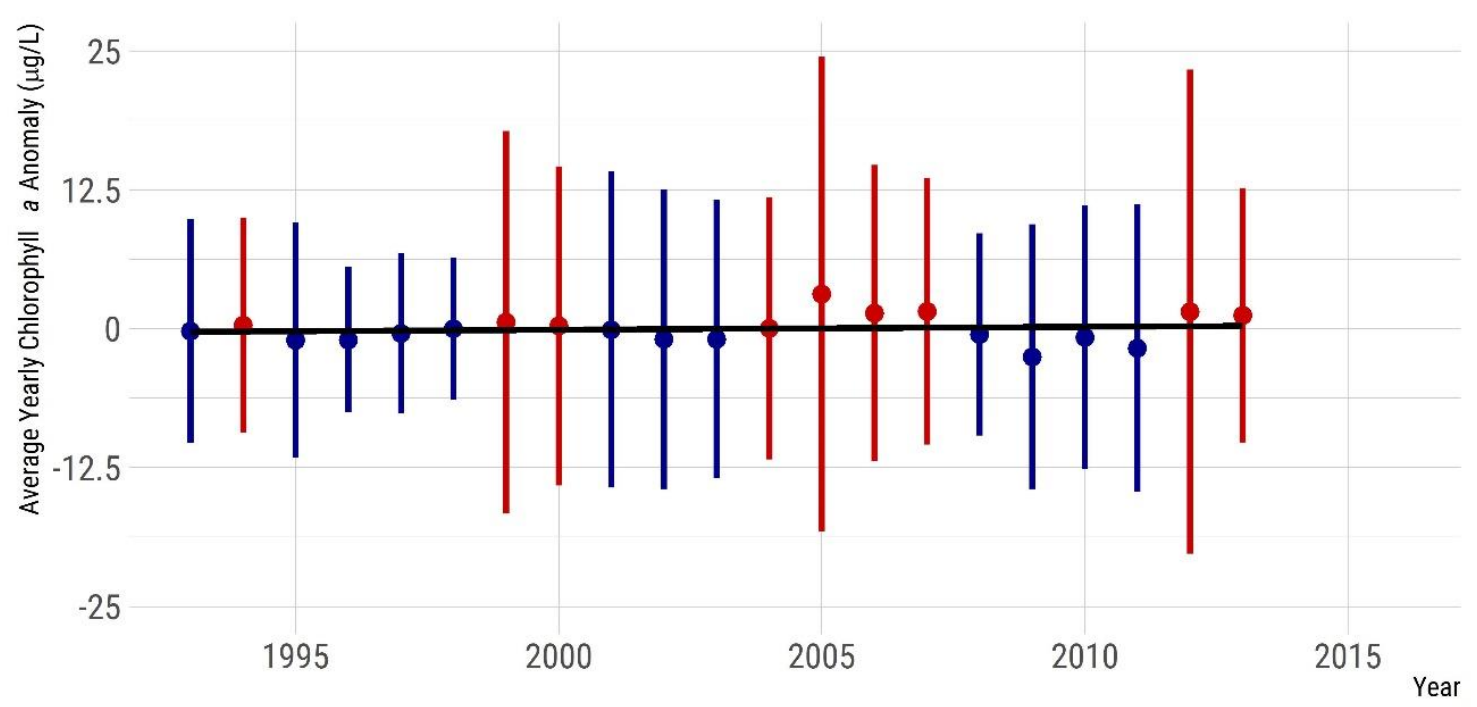

247 Figure 4: Yearly trend over 20+ years of chlorphyll a (mean anomaly). Panel A. Yearly mean chlorophyll a anomalies from the URI Watershed Watch data. Panel B. Yearly mean chlorophyll a anomalies from the LAGOSNE dataset. Points are means of site-specific anomalies and ranges are standard deviations of site-specific anomalies. Blue indicates yearly site-specific anomalies that were, on average, below the site-specific long-term means. Red indicates yearly site-specific anomalies that were, on average, above the site-specific longterm means. 


\section{A. URI Watershed Watch Total Nitrogen}

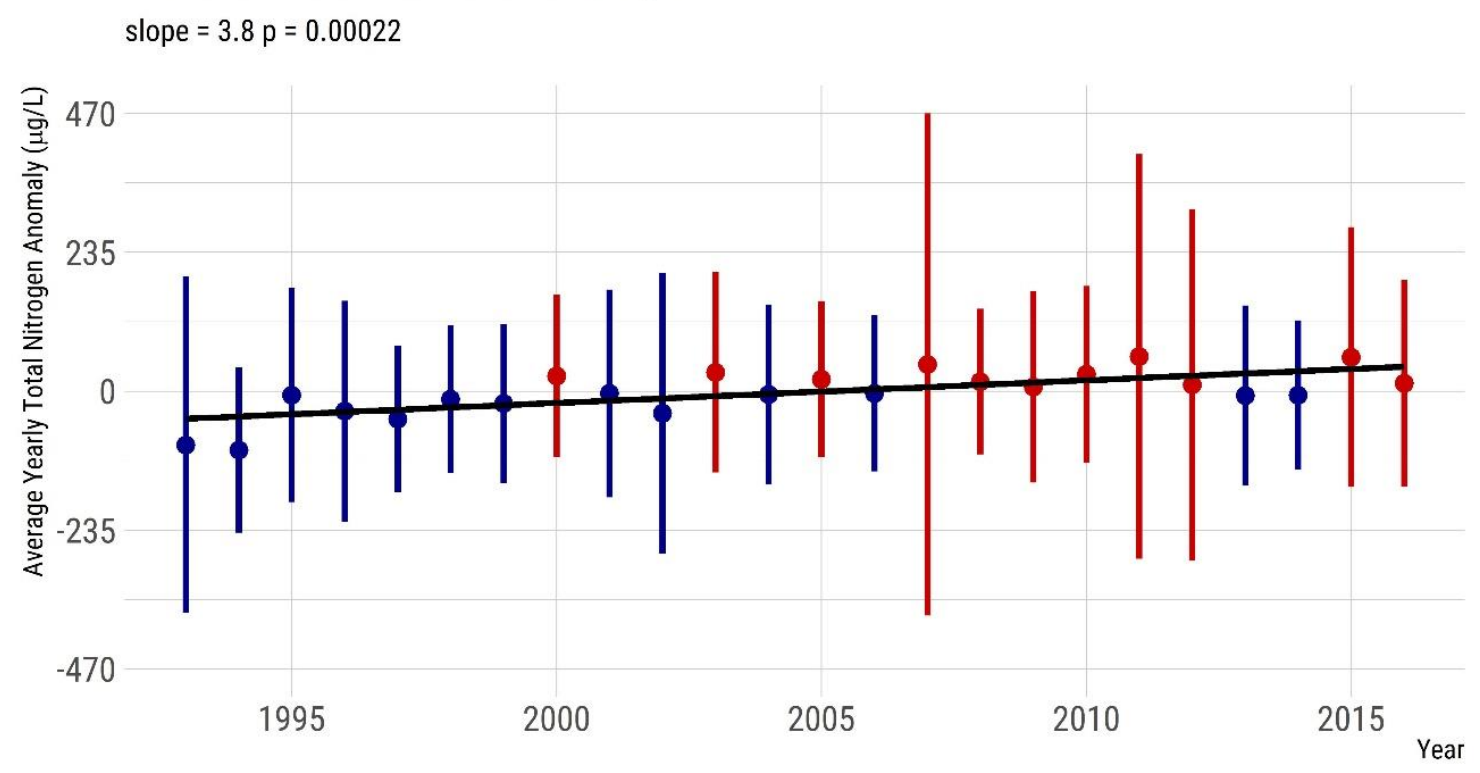

\section{B. LAGOSNE Total Nitrogen}

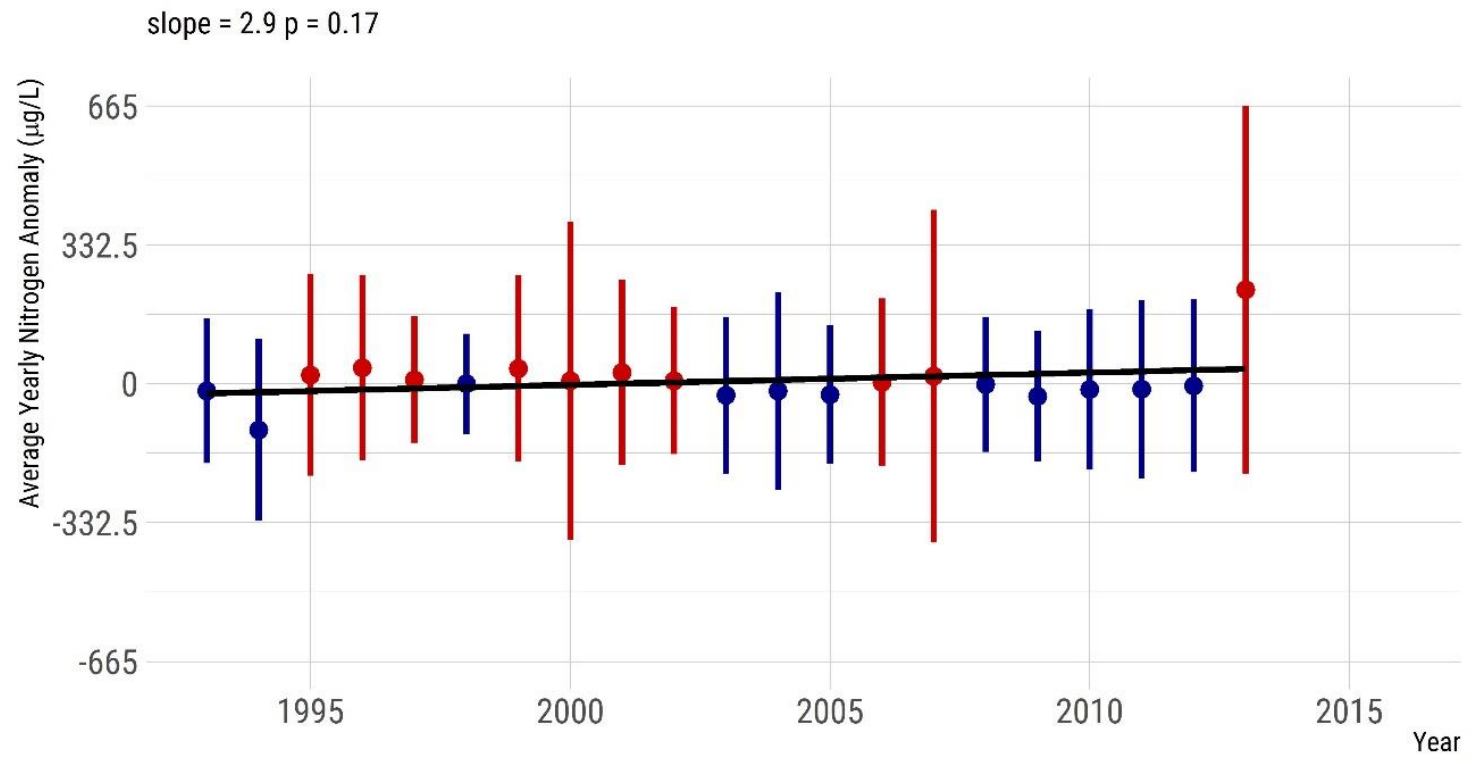

Figure 5: Yearly trend over 20+ years of TN (mean anomaly). Panel A. Yearly mean TN anomalies from the URI Watershed Watch dataset. Panel B. Yearly mean TN anomalies from the LAGOSNE dataset. Points are means of site-specific anomalies and ranges are standard deviations of site-specific anomalies. Blue indicates yearly site-specific anomalies that were, on average, below the site-specific long-term means. Red indicates yearly site-specific anomalies that were, on average, above the site-specific long-term means. 


\section{A. URI Watershed Watch Total Phosphorus}

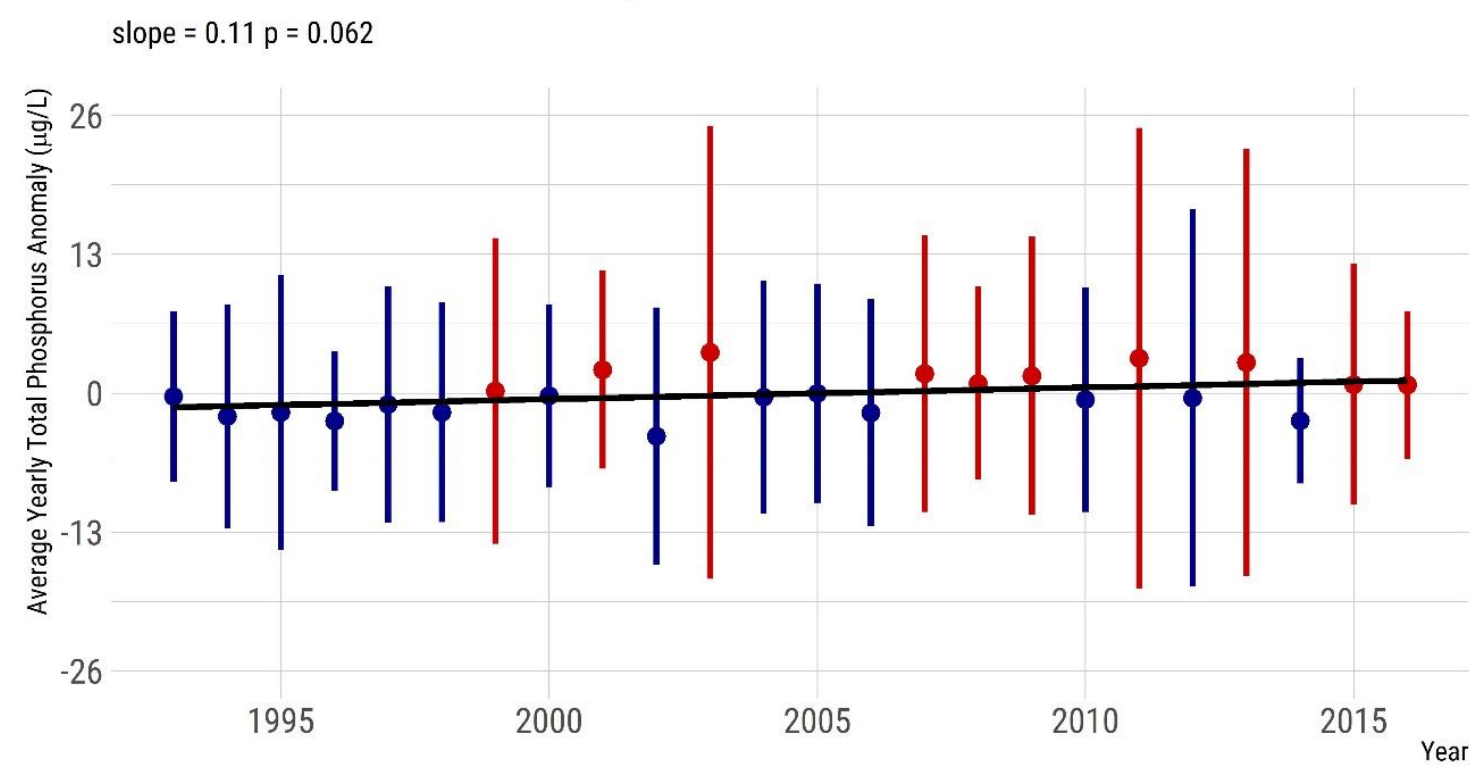

\section{B. LAGOSNE Total Phosphorus}

slope $=-0.027 p=0.32$

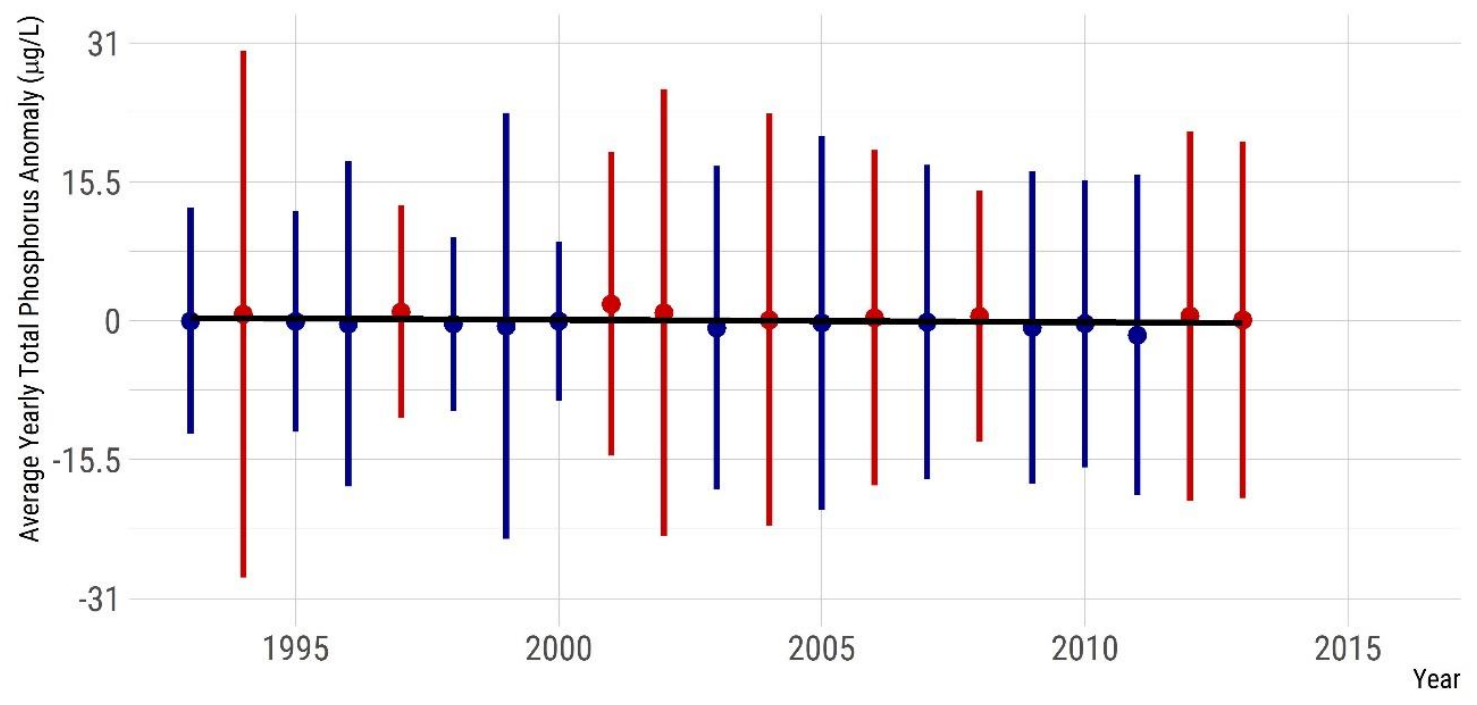

Figure 6: Yearly trend over 20+ years of TP (mean anomaly). Panel A. Yearly mean TP anomalies from the URI Watershed Watch dataset. Panel B. Yearly mean TP anomalies from the LAGOSNE dataset. Points are means of site-specific anomalies and ranges are standard deviations of site-specific anomalies. Blue indicates yearly site-specific anomalies that were, on average, below the site-specific long-term means. Red indicates yearly site-specific anomalies that were, on average, above the site-specific long-term means. 


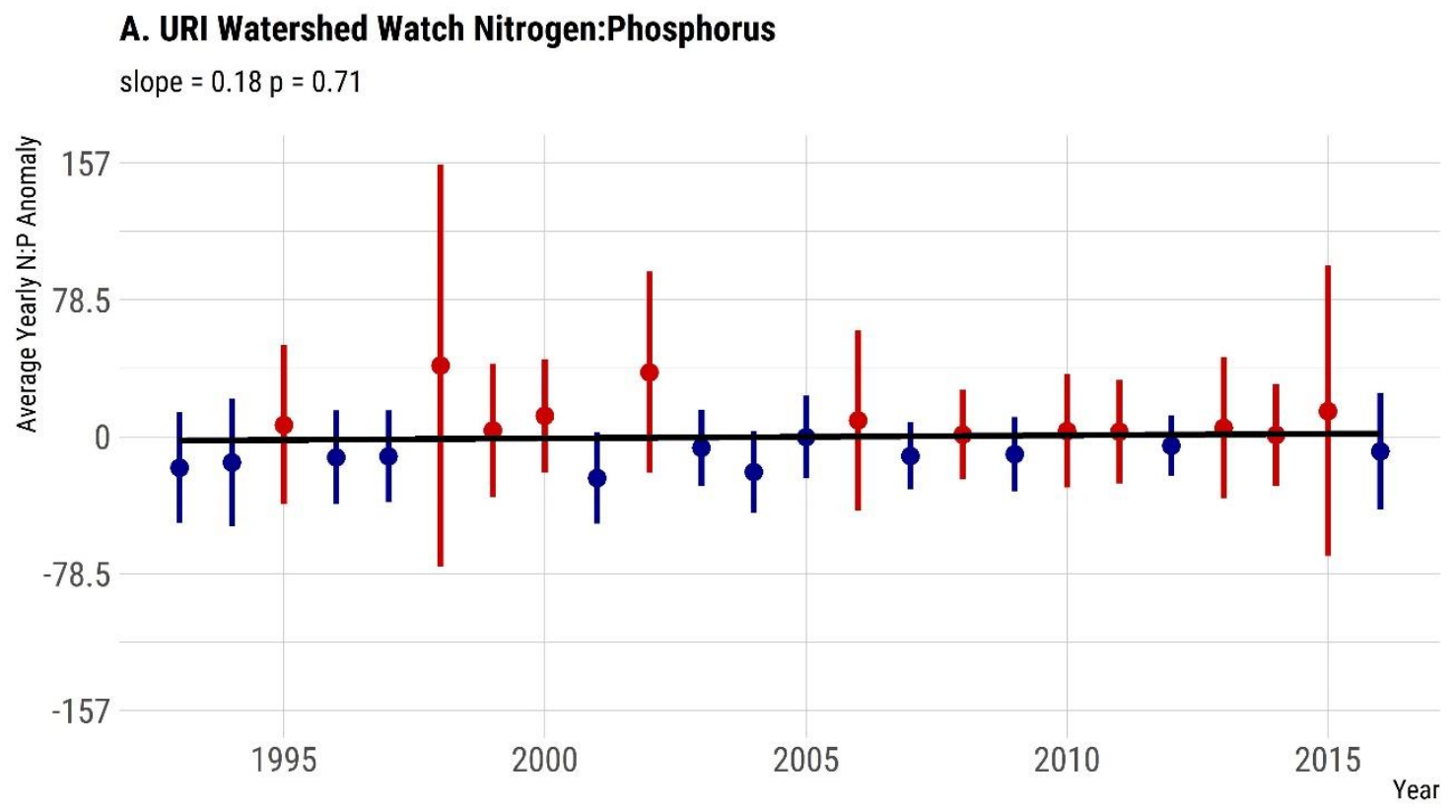

B. LAGOSNE Nitrogen:Phosphorus

slope $=0.086 p=0.74$

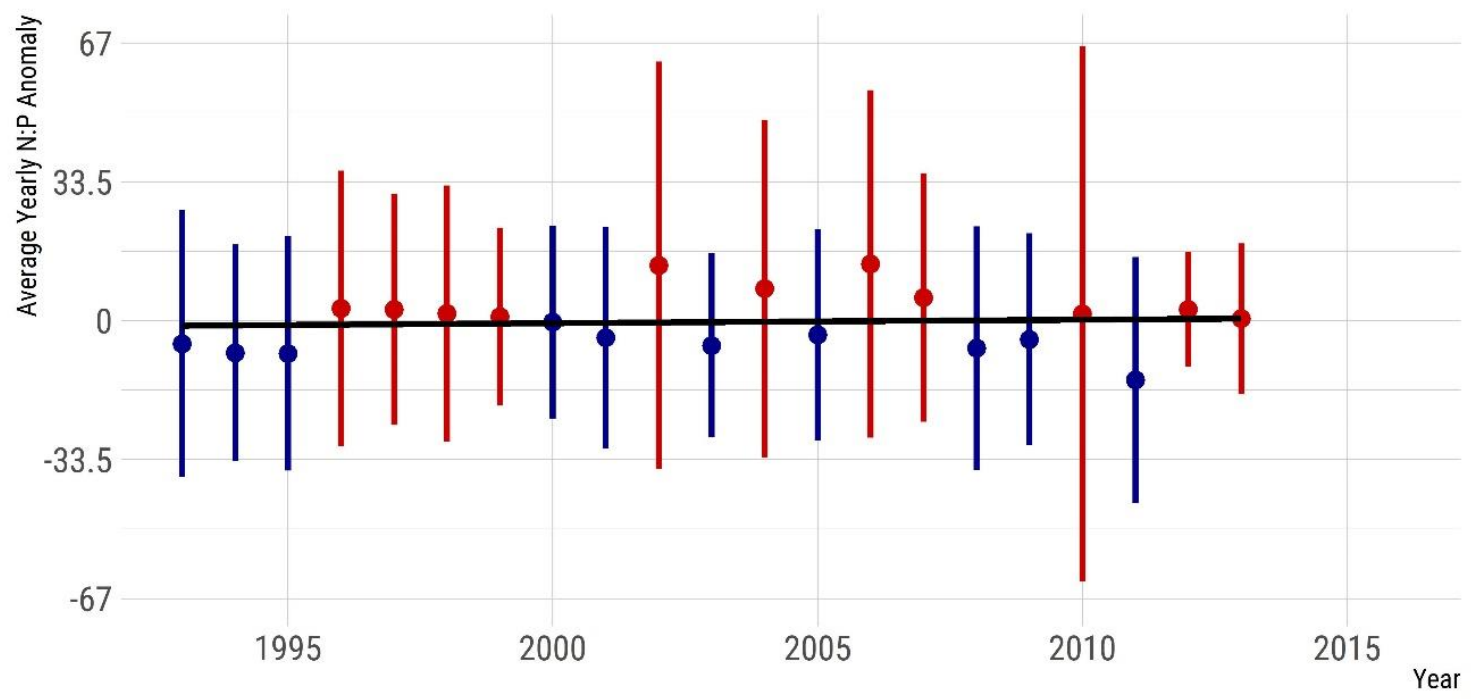

269 Figure 7: Yearly trend over 20+ years of the TN:TP ratio (mean anomaly). Panel A. Yearly mean TN:TP ratio anomalies from the URI Watershed Watch dataset. Panel B. Yearly mean TN:TP ratio anomalies from the LAGOSNE dataset. Points are means of site-specific anomalies and ranges are standard deviations of site-specific anomalies. Blue indicates yearly sitespecific anomalies that were, on average, below the site-specific long-term means. Red indicates yearly site-specific anomalies that were, on average, above the site-specific long-

275 term means. 


\subsection{Regional trends in water quality}

277 In general, there was little evidence to suggest broad regional changes. Chlorophyll $a$ 278 showed a very weak positive trend (slope $=0.027, \mathrm{p}=0.58$, Figure 4B.), TP showed a slight 279 decreasing trend (slope $=-0.027, \mathrm{p}=0.32$, Figure 6B.), TN showed a slight positive trend 280 (slope $=2.9, \mathrm{p}=0.17$, Figure 5B.) and the TN:TP showed little change (slope $=0.086, \mathrm{p}=$ 281 0.74, Figure 7B.)

\section{Discussion and conclusions}

283 Our sub-regional analysis indicates that even when nutrient regimes exhibit relative 284 stability (i.e., neither increasing nor decreasing over time), increases in primary 285 production, as measured by chlorophyll $a$, can occur. Over the same period we also 286 demonstrate long-term warming of Rhode Island lakes and reservoirs. Chlorophyll has 287 increased, on average, $0.29 \mu \mathrm{g} / \mathrm{L}$ per year over the 23 years of our analysis, while 288 temperature has increased $0.053^{\circ} \mathrm{C}$ per year over the same period. This suggests that the 289 observed increase in productivity, as measured by chlorophyll $a$, may be a result of 290 warming waters and not a response to changes in nutrient condition. Also, geographic 291 extent does indeed matter when trying to identify long-term water quality trends. Similar 292 to the results of Oliver et al. (2017) our analysis shows little increasing trend in chlorophyll $293 a$ at the regional scale (e.g., northeastern and mid-western United States). However, at the

294 local scale of the state of Rhode Island, there is a clear increasing trend in chlorophyll $a$.

\section{$295 \quad 4.1$ Trends}

296 As previously mentioned, both temperature and chlorophyll $a$ show increasing trends from

2971993 to 2016 in Rhode Island lakes and reservoirs; while total nutrients and the TN:TP

298 ratio are all relatively stable. While TN showed a weak positive trend, that trend was

299 largely driven by the unusually low years for TN in 1993 and 1994. With those removed the 300 positive trends weakens considerably. The general picture in Rhode Island appears to be 301 one of little to no change in phosphorus, a very weak positive trend in nitrogen and little to 302 no change in the TN:TP ratio. Furthermore, it has been shown that productivity in

303 freshwater systems is likely a function of both phosphorus and nitrogen (Paerl et al. 2016). 
304 Thus, the increasing chlorophyll $a$ in the face of stable TN:TP ratio suggests that the

305 increase is being driven by something other than nutrients. We interpret these results as

306 relative stability in nutrients in Rhode Island lakes and reservoirs.

307 Stable nutrient regimes may be partly explained by efforts to curb nutrient loadings, for

308 example through voluntary and state wide mandatory bans on phosphates in laundry

309 detergent which were implemented in Rhode Island in 1995 (Rhode Island State

310 Legislature 1995, Litke 1999). However, in many lakes there are still likely sufficient

311 nutrients present to allow for increases in chlorophyll $a$. Additionally, these results point to

312 the fact that chlorophyll $a$ and algal biomass is driven by processes operating at different

313 scales. For instance, nutrient management is largely a local to watershed scale effort, but

314 may also be regional as atmospheric nitrogen deposition can be a significant source of

315 nitrogen (Boyer et al. 2002). Similarly, warming lakes are driven by broader climate

316 patterns, yet waterbody-specific factors such as the percent of a catchment that is

317 impervious surface and lake morphology can also impact temperature (Nelson and Palmer

318 2007). In short, differences in regional and state level trends are driven by complex and

319 multi-scale processes.

320 In addition to the annualized trends of the five variables we address with this study, there

321 are other trends that may be of interest. For example, trends for water quality at finer

322 temporal scales such as monthly or seasonal trends may be different than the annual

323 trends we analyzed. Anecdotal evidence in Rhode Island points to warmer temperature

324 earlier and later in the year and suggests a lengthening of the growing season.

325 Furthermore, preliminary analysis of the URIWW data back this up with mean temperature

326 for May 1993 to May 1995 cooler by nearly a degree than mean temperature for May 2014

327 through May 2016. Additionally, it may be possible that the current trophic state of a given

328 waterbody may partly explain the chlorophyll $a$ changes in that lake. For instance, are

329 oligotrophic lakes showing stronger trends than eutrophic lakes or are all lakes showing

330 similar trends regardless of current trophic status? Lastly, changes in rainfall, extreme

331 weather events, or other climate mediated factors can also be playing a role in increasing

332 chlorophyll in Rhode Island lakes and reservoirs. These questions are beyond the scope of

333 this study, but all warrant further, careful investigation. 


\section{$334 \quad 4.2$ Management implications}

335 There are several broader management implications from the results of our analysis and of

336 examining long-term water quality trends in general. In particular, this analysis provides

337 much needed information about the long-term effects of current nutrient control efforts at

338 lake-specific and sub-regional scales and identifies areas where additional information is

339 required or a change in management approaches may be needed. First, as more long-term

340 datasets become available, it is important for managers and stakeholders to receive

341 feedback on long-term water quality trends at multiple spatial scales. Specifically for this

342 study, the results provide feedback to long time volunteer monitors, highlighting the

343 importance of volunteer monitoring programs. Second, with information on long-term

344 trends, it is possible to adapt management approaches to address areas of concern. Our

345 results show increasing chlorophyll $a$ even though the general long-term nutrient trends

346 have been stable. This suggests the need to further reduce nutrients to compensate for

347 warmer water temperatures and possible longer growing seasons.

348 There are several possible approaches to further reduce nutrient loads (Yang and Lusk

349 2018). First, nutrient load reductions may be possible through source controls and

350 enhanced entrainment and treatment of ground and surface waters transporting nutrients

351 to receiving waters (Kellogg et al. 2010). Green infrastructure approaches are one way to

352 possibly achieve both goals (Pennino et al. 2016, Reisinger et al. 2019). Additionally, there

353 is potential for within-lake approaches such as the restoration of freshwater mussels to

354 waterbodies that historically had those species. Some studies using freshwater mussels

355 have shown reductions in both nutrients and algal biomass (Kreeger et al. 2018).

\section{$356 \quad 4.3$ Data analysis approach}

357 The analysis approach we used here, site-specific anomalies, is not a novel method and

358 does have a long history in the analysis of trends in climate (Jones and Hulme 1996, Jones

359 et al. 1999, Hansen et al. 2006, 2010). However, using it to examine water quality trends is

360 a new application of the technique, as we could find little evidence of using it specifically

361 for water quality trends. We built on these methods and adapted them for use with long-

362 term water quality trends. While other methods are valid and robust (e.g., Oliver et al. 
2017), we chose mean site-specific anomalies as they can provide readily interpretable

364 results, especially for communicating to general audiences. For instance, reporting the

365 changes in anomalies allows us to look at changes in the original units. With our analysis,

366 the slope of the regression line for temperature suggests a mean yearly increase of $0.053^{\circ} \mathrm{C}$

367 and the slope of the regression line for chlorophyll $a$ shows a mean yearly increase of 0.29

$368 \mu \mathrm{g} / \mathrm{l}$. Additionally, the site-specific anomalies are robust to variations in sampling effort

369 and in the timing of inclusion of given sampling locations (e.g., added later in a time period

370 or removed). Lastly, this analysis is only possible because of the availability of sound, long-

371 term data on water quality in Rhode Island. Without the URIWW data and the commitment

372 and participation of more than 2500 volunteers over the years, our analyses would have

373 been impossible. Going forward, it is important to appreciate the role that volunteer

374 monitoring and citizen science programs can play in capturing and better understanding

375 long term environmental trends.

376

377

378

379

380

381

382

383

384

385

386

387

388

389

390

391

392

393

394

395

\section{Bibliography}

Boyer, E. W., C. L. Goodale, N. A. Jaworski, and R. W. Howarth. 2002. Anthropogenic nitrogen sources and relationships to riverine nitrogen export in the northeastern usa. Biogeochemistry 57:137-169.

Brooks, B. W., J. M. Lazorchak, M. D. Howard, M.-V. V. Johnson, S. L. Morton, D. A. Perkins, E. D. Reavie, G. I. Scott, S. A. Smith, and J. A. Steevens. 2016. Are harmful algal blooms becoming the greatest inland water quality threat to public health and aquatic ecosystems? Environmental Toxicology and Chemistry 35:6-13.

Carpenter, S. R., N. F. Caraco, D. L. Correll, R. W. Howarth, A. N. Sharpley, and V. H. Smith. 1998. Nonpoint pollution of surface waters with phosphorus and nitrogen. Ecological Applications 8:559-568.

Cheruvelil, K., P. Soranno, K. Webster, and M. Bremigan. 2013. Multi-scaled drivers of ecosystem state: Quantifying the importance of the regional spatial scale. Ecological Applications 23:1603-1618.

Collins, S. M., S. K. Oliver, J.-F. Lapierre, E. H. Stanley, J. R. Jones, T. Wagner, and P. A. Soranno. 2017. Lake nutrient stoichiometry is less predictable than nutrient concentrations at regional and sub-continental scales. Ecological applications 27:1529-1540.

Dickinson, J. L., J. Shirk, D. Bonter, R. Bonney, R. L. Crain, J. Martin, T. Phillips, and K. Purcell. 2012. The current state of citizen science as a tool for ecological research and public engagement. Frontiers in Ecology and the Environment 10:291-297. 
Dodds, W. K., W. W. Bouska, J. L. Eitzmann, T. J. Pilger, K. L. Pitts, A. J. Riley, J. T. Schloesser, and D. J. Thornbrugh. 2008. Eutrophication of us freshwaters: Analysis of potential economic damages. ACS Publications.

399 Filippelli, G. M. 2008. The global phosphorus cycle: Past, present, and future. Elements 4:89-95.

401 Filstrup, C. T., T. Wagner, S. K. Oliver, C. A. Stow, K. E. Webster, E. H. Stanley, and J. A.

402 Downing. 2018. Evidence for regional nitrogen stress on chlorophyll a in lakes across large landscape and climate gradients. Limnology and Oceanography 63:S324-S339.

404 Filstrup, C. T., T. Wagner, P. A. Soranno, E. H. Stanley, C. A. Stow, K. E. Webster, and J. A. Downing. 2014. Regional variability among nonlinear chlorophyll-phosphorus relationships in lakes. Limnology and Oceanography 59:1691-1703.

407 Finlay, J. C., G. E. Small, and R. W. Sterner. 2013. Human influences on nitrogen removal in 408 lakes. Science 342:247-250.

409 Hansen, J., R. Ruedy, M. Sato, and K. Lo. 2010. Global surface temperature change. Reviews 410 of Geophysics 48.

411 Hansen, J., M. Sato, R. Ruedy, K. Lo, D. W. Lea, and M. Medina-Elizade. 2006. Global

412 temperature change. Proceedings of the National Academy of Sciences 103:14288-14293.

413 Helsel, D., and R. Hirsch. 2002. Statistical methods in water resources. Techniques of 414 Water-Resources Investigations Book 4:395.

415 Herlihy, A. T., N. C. Kamman, J. C. Sifneos, D. Charles, M. D. Enache, and R. J. Stevenson. 2013. Using multiple approaches to develop nutrient criteria for lakes in the conterminous USA.

417 Freshwater Science 32:367-384.

418 Hollister, J. W., D. Q. Kellogg, B. J. Kreakie, S. S. Shivers, B. W. Milstead, E. Herron, L. Green, 419 and A. Gold. 2019.. Zenodo - complete citation when paper submited.

420 Hollister, J. W., W. B. Milstead, and B. J. Kreakie. 2016. Modeling lake trophic state: A 421 random forest approach. Ecosphere 7.

422 Hurlbert, S. H. 1984. Pseudoreplication and the design of ecological field experiments. 423 Ecological monographs 54:187-211.

424 Jones, P. D., M. New, D. E. Parker, S. Martin, and I. G. Rigor. 1999. Surface air temperature 425 and its changes over the past 150 years. Reviews of Geophysics 37:173-199.

426 Jones, P., and M. Hulme. 1996. Calculating regional climatic time series for temperature and precipitation: Methods and illustrations. International Journal of Climatology: A Journal of 428 the Royal Meteorological Society 16:361-377.

429 Kellogg, D., A. J. Gold, S. Cox, K. Addy, and P. V. August. 2010. A geospatial approach for 430 assessing denitrification sinks within lower-order catchments. Ecological Engineering $431 \quad 36: 1596-1606$. 
432 Kosmala, M., A. Wiggins, A. Swanson, and B. Simmons. 2016. Assessing data quality in 433 citizen science. Frontiers in Ecology and the Environment 14:551-560.

434 Kosten, S., V. L. Huszar, E. Bécares, L. S. Costa, E. Van Donk, L.-A. Hansson, E. Jeppesen, C. 435 Kruk, G. Lacerot, N. Mazzeo, and others. 2012. Warmer climates boost cyanobacterial 436 dominance in shallow lakes. Global Change Biology 18:118-126.

437 Kreeger, D. A., C. M. Gatenby, and P. W. Bergstrom. 2018. Restoration potential of several native species of bivalve molluscs for water quality improvement in mid-atlantic watersheds. Journal of Shellfish Research 37:1121-1158.

440 Litke, D. W. 1999. Review of phosphorus control measures in the united states and their effects on water quality. Water-Resources Investigations Report 99:4007.

442 Lottig, N. R., P.-N. Tan, T. Wagner, K. S. Cheruvelil, P. A. Soranno, E. H. Stanley, C. E. Scott, C. 443 A. Stow, and S. Yuan. 2017. Macroscale patterns of synchrony identify complex 444 relationships among spatial and temporal ecosystem drivers. Ecosphere 8:12.

445 Lottig, N. R., T. Wagner, E. N. Henry, K. S. Cheruvelil, K. E. Webster, J. A. Downing, and C. A. 446 Stow. 2014. Long-term citizen-collected data reveal geographical patterns and temporal 447 trends in lake water clarity. PLoS ONE 9:e95769.

448 Michalak, A. M., E. J. Anderson, D. Beletsky, S. Boland, N. S. Bosch, T. B. Bridgeman, J. D. Chaffin, K. Cho, R. Confesor, I. Daloğlu, and others. 2013. Record-setting algal bloom in lake erie caused by agricultural and meteorological trends consistent with expected future conditions. Proceedings of the National Academy of Sciences 110:6448-6452.

452 Nelson, K. C., and M. A. Palmer. 2007. Stream temperature surges under urbanization and climate change: Data, models, and responses 1. JAWRA Journal of the American Water 454 Resources Association 43:440-452. state index. PeerJ Preprints.

457 Oliver, S. K., S. M. Collins, P. A. Soranno, T. Wagner, E. H. Stanley, J. R. Jones, C. A. Stow, and N. R. Lottig. 2017. Unexpected stasis in a changing world: Lake nutrient and chlorophyll trends since 1990. Global Change Biology 23:5455-5467.

460 Paerl, H. W., and J. Huisman. 2009. Climate change: A catalyst for global expansion of 461 harmful cyanobacterial blooms. Environmental Microbiology Reports 1:27-37.

462 Paerl, H. W., J. T. Scott, M. J. McCarthy, S. E. Newell, W. S. Gardner, K. E. Havens, D. K. 463 Hoffman, S. W. Wilhelm, and W. A. Wurtsbaugh. 2016. It takes two to tango: When and 464 where dual nutrient (N \& P) reductions are needed to protect lakes and downstream 465 ecosystems. Environmental Science \& Technology 50:10805-10813.

466 Pennino, M. J., R. I. McDonald, and P. R. Jaffe. 2016. Watershed-scale impacts of stormwater green infrastructure on hydrology, nutrient fluxes, and combined sewer overflows in the mid-atlantic region. Science of the Total Environment 565:1044-1053. 
Read, E. K., V. P. Patil, S. K. Oliver, A. L. Hetherington, J. A. Brentrup, J. A. Zwart, K. M. Winters, J. R. Corman, E. R. Nodine, R. I. Woolway, and others. 2015. The importance of lake-specific characteristics for water quality across the continental United States. Ecological Applications 25:943-955.

473 Reisinger, A. J., E. Woytowitz, E. Majcher, E. J. Rosi, K. T. Belt, J. M. Duncan, S. S. Kaushal, and P. M. Groffman. 2019. Changes in long-term water quality of baltimore streams are associated with both gray and green infrastructure. Limnology and Oceanography 64:S60476 S76.

477 Rhode Island State Legislature. 1995. Phosphate reduction act of 1995.

478 Schindler, D. 2009. Lakes as sentinels and integrators for the effects of climate change on 479 watersheds, airsheds, and landscapes. Limnology and Oceanography 54:2349-2358.

480 Schindler, D. W., R. Hecky, D. Findlay, M. Stainton, B. Parker, M. Paterson, K. Beaty, M. Lyng, and S. Kasian. 2008. Eutrophication of lakes cannot be controlled by reducing nitrogen input: Results of a 37-year whole-ecosystem experiment. Proceedings of the National Academy of Sciences 105:11254-11258.

Smith, V. H. 2003. Eutrophication of freshwater and coastal marine ecosystems a global problem. Environmental Science and Pollution Research 10:126-139. NE: A multi-scaled geospatial and temporal database of lake ecological context and water quality for thousands of US lakes. Gigascience 6.

489 Soranno, P. A., E. G. Bissell, K. S. Cheruvelil, S. T. Christel, S. M. Collins, C. E. Fergus, C. T. 490 Filstrup, J.-F. Lapierre, N. R. Lottig, S. K. Oliver, and others. 2015. Building a multi-scaled geospatial temporal ecology database from disparate data sources: Fostering open science and data reuse. GigaScience 4:28.

Stachelek, J., and S. Oliver. 2017. LAGOSNE: Interface to the lake multi-scaled geospatial and temporal database, R package version 1.1.0. https://cran.r-project.org/package=LAGOSNE.

495 Stoddard, J. L., J. Van Sickle, A. T. Herlihy, J. Brahney, S. Paulsen, D. V. Peck, R. Mitchell, and A. I. Pollard. 2016. Continental-scale increase in lake and stream phosphorus: Are oligotrophic systems disappearing in the united states? Environmental Science \& Technology 50:3409-3415.

499 Taranu, Z. E., I. Gregory-Eaves, P. R. Leavitt, L. Bunting, T. Buchaca, J. Catalan, I. Domaizon, P. Guilizzoni, A. Lami, S. McGowan, and others. 2015. Acceleration of cyanobacterial dominance in north temperate-subarctic lakes during the anthropocene. Ecology Letters 502 18:375-384.

503 Vitousek, P. M., J. D. Aber, R. W. Howarth, G. E. Likens, P. A. Matson, D. W. Schindler, W. H. 504 Schlesinger, and D. G. Tilman. 1997. Human alteration of the global nitrogen cycle: Sources 505 and consequences. Ecological Applications 7:737-750. 
506 Wasserstein, R. L., N. A. Lazar, and others. 2016. The ASA's statement on p-values: Context, 507 process, and purpose. The American Statistician 70:129-133.

508 Williamson, C. E., W. Dodds, T. K. Kratz, and M. A. Palmer. 2008. Lakes and streams as 509 sentinels of environmental change in terrestrial and atmospheric processes. Frontiers in 510 Ecology and the Environment 6:247-254.

511 Yang, Y.-Y., and M. G. Lusk. 2018. Nutrients in urban stormwater runoff: Current state of the 512 science and potential mitigation options. Current Pollution Reports 4:112-127.

513 Yuan, L. L., A. I. Pollard, S. Pather, J. L. Oliver, and L. D'Anglada. 2014. Managing microcystin: 514 Identifying national-scale thresholds for total nitrogen and chlorophyll a. Freshwater 515 biology 59:1970-1981. 